\title{
Breathing pattern and thoracoabdominal motion during exercise in chronic obstructive pulmonary disease
}

\author{
G.S. Alves, R.R. Britto, F.C. Campos, A.B.O. Vilaça, K.S. Moraes and V.F. Parreira \\ Departamento de Fisioterapia, Escola de Educação Física, Fisioterapia e Terapia Ocupacional, \\ Universidade Federal de Minas Gerais, Belo Horizonte, MG, Brasil
}

Correspondence to: R.R. Britto, Departamento de Fisioterapia, UFMG, Av. Antônio Carlos, 6627, 31270-901 Belo Horizonte, MG, Brasil

Fax: +55-31-3409-4783. E-mail: rbrito@ufmg.br

Subjects with chronic obstructive pulmonary disease (COPD) present breathing pattern and thoracoabdominal motion abnormalities that may contribute to exercise limitation. Twenty-two men with stable COPD $\left(\mathrm{FEV}_{1}=42.6 \pm 13.5 \%\right.$ predicted; age 68 \pm 8 years; mean \pm SD) on usual medication and with at least 5 years of diagnosis were evaluated at rest and during an incremental cycle exercise test (10 watts/2 $\mathrm{min}$ ). Changes in respiratory frequency, tidal volume, rib cage and abdominal motion contribution to tidal volume and the phase angle that measures the asynchrony were analyzed by inductive respiratory plethysmography at rest and during three levels of exercise (30-50, 70-80, and 100\% maximal work load). Repeated measures ANOVA followed by pre-planned contrasts and Bonferroni corrections were used for analyses. As expected, the greater the exercise intensity the higher the tidal volume and respiratory frequency. Abdominal motion contributed to the tidal volume increase (rest: $49.82 \pm 11.19 \%$ vs exercise: $64.15 \pm 9.7 \%, 63.41 \pm 10 \%$, and $65.56 \pm 10.2 \%$, respectively, $\mathrm{P}<0.001$ ) as well as the asynchrony [phase angle: $11.95 \pm 7.24^{\circ}$ at rest vs $22.2 \pm 15^{\circ}(P=0.002), 22.6 \pm 9^{\circ}(P<0.001)$, and $22.7 \pm 8^{\circ}(P<0.001)$, respectively, at the three levels of exercise]. In conclusion, the increase in ventilation during exercise in COPD patients was associated with the major motion of the abdominal compartment and with an increase in the asynchrony independent of exercise intensity. It suggests that cycling exercise is an effective way of enhancing ventilation in COPD patients.

Key words: Breathing pattern; Chronic obstructive pulmonary disease; Exercise; Plethysmography; Ventilation

Research supported by FAPEMIG (\#CDS-855/05). R.R. Britto and V.F. Parreira are established investigators of CNPq, grants \#303420/2005-7 and \#309145/2007-4 and FAPEMIG, grants \#CDS-APQ-4663-5.01/07 and \#CDS-APQ-5350-5.01/07, respectively.

Received October 22, 2007. Accepted November 5, 2008

\section{Introduction}

Breathlessness and exercise intolerance are the most common symptoms in chronic obstructive pulmonary disease (COPD) and limit the patients' participation in daily and social activities (1). Dynamic hyperinflation contributes greatly to the limitation of exercise tolerance in most patients with COPD (2). In addition, maximal ventilation during exercise is often limited by the mechanical constraints imposed by the lung pathophysiology (3). The presence of the mechanical disadvantages contributes to abnormalities in thoracoabdominal motion at rest (4) and during exercise (5).

Pulmonary rehabilitation programs have been focusing on strategies to improve alveolar ventilation such as diaphragmatic breathing that seems to be related to modifications of breathing pattern (6). Studies have reported a decrease in rib cage motion and an increase in abdominal motion during diaphragmatic breathing $(7,8)$.

Few studies have described thoracoabdominal motion during exercise in COPD $(5,9,10)$. During incremental exercise on a treadmill, Delgado et al. (5) using respiratory inductive plethysmography, demonstrated a paradoxical motion that was associated with the severity of the exer- 
cise limitation. Dodd et al. (9) and Grimby et al. (10) reported a tendency to increase the relative contribution of the abdomen to tidal volume more in COPD patients than in healthy subjects during cycling exercise. However, it is not clear if the increase of the abdominal motion is related to exercise intensity, which is an important variable when prescribing exercise in pulmonary rehabilitation.

The objective of the present study was to determine the breathing pattern and thoracoabdominal motion of subjects with COPD at three cycling exercise intensities.

\section{Subjects and Methods}

\section{Subjects}

Twenty-two men with stable COPD diagnosed by accepted criteria (11) were selected among subjects with COPD admitted for treatment at a university-based hospital. Patients with ages ranging from 50 to 80 years, forced expiratory volume in one second $\left(\mathrm{FEV}_{1}\right)$ under $80 \%$ of the predicted value, $\mathrm{FEV}_{1} /$ forced vital capacity (FVC) lower than 0.7 and body mass index between 18 and 30 were included. All patients were former smokers and none had any clinical or physiological features of bronchial asthma or a history of exacerbation in the previous 6 weeks. There were no co-morbidities limiting exercise. The patients were receiving medical therapy with usual pulmonary drugs and none of them was taking part in a regular physical activity program. The Ethics Research Committee of the Universidade Federal de Minas Gerais approved the protocol and written informed consent was obtained.

\section{Experimental protocol}

The experiments were carried out with the patients in the same position, seated on a mechanical MAXX Pro cycle ergometer (Monark standard, Hydrofit ${ }^{\circledR}$, Brazil) at rest and during exercise. All subjects were familiarized with exercise testing. The resting breathing data were recorded for at least $2 \mathrm{~min}$. The patients began the exercise with a workload of 10 or 20 watts (12), which was increased progressively by 10 watts every 2 min until exhaustion. Supplementary oxygen was offered if transcutaneous oxygen saturation $\left(\mathrm{SpO}_{2}\right)$ decreased to values lower than $88 \%$ (13). The interruption criteria for exercise tests were based on the American College of Sports Medicine (ACSM) and strictly followed (14). Respiratory variables were measured continuously at rest and during exercise.

\section{Measurements}

Respiratory frequency (f), tidal volume (Vt), minute ventilation (VE), rib cage (RC), the contribution of abdominal $(A B)$ motion to $V t(\% R C, \% A B)$ and the phase angle
(PhaseAng) were obtained by respiratory inductive plethysmography (Respitrace ${ }^{\circledR}$, Nims, USA) with the following waveform characteristics: 50 samples per second of sample rate, $1 \mathrm{mV}$ per bit of resolution and a flow filter with a delay period of $100 \mathrm{~ms}$. This means that a moving window derivative is taken $100 \mathrm{~ms}$ before and after each advancing point of volume trace. The accuracy of plethysmography in the evaluation of breathing pattern has been determined at rest and during physical activity in both adults and children (15).

Teflon-coated inductance coils of appropriate size were placed around the rib cage (at the level of the axilla) and abdomen (at the level of the umbilicus). An elastic mesh bandage was worn over the bands to minimize movement artifacts (16) and the subject was positioned on the cycle ergometer. Relative electrical gains ( $400 \mathrm{mV}=100 \% \mathrm{Vt}$ ) of the $R C$ and $A B$ channels were obtained using the qualitative diagnostic calibration procedure (QDC) for 5 min of natural breathing (17) using the computer software (RespiPanel 4.0, Nims) that was based on the equations proposed by Sackner et al. (17) to calculate the proportionality constant $(K)$ between $\mathrm{RC}$ and $\mathrm{AB}$ amplifiers and in the adjustment of the ratio of the two signals informed when QDC was completed. QDC is used to set the gains of the two channels so their sum corresponds to lung volume. Subsequently, to obtain the respiratory inductive plethysmographic sum signal for absolute volume in $\mathrm{mL}$, a quantitative calibration was carried out with the subject breathing into the spirometer (Vitatrace, Pro Médico, Brazil) through a mouthpiece with the nose clipped for 30 to $60 \mathrm{~s}$ $(18,19)$ and electrical spirometer output was recorded with a computer. The spirometer was calibrated with a 3-liter syringe (Hans Rudolph Inc., USA) using the software RespiPanel and signals were recorded with a digital acquisition system (RespiEvents 5.2, Nims) at rest and during three intensity levels of exercise.

The second minute cut-off tracings corresponding to mild, moderate and maximal exercise (30-50, 70-80, and $100 \%$ of maximal workload reached, respectively) were used for analysis. When the rib cage and abdomen move in perfect synchrony, PhaseAng $=0^{\circ}$. With the increase of asynchronous thoracoabdominal motion, PhaseAng increases to $180^{\circ}$, the point at which the rib cage and abdomen are completely out of phase (20). $\mathrm{SpO}_{2}$ was continuously monitored during exercise by pulse oximetry (Datex-Ohmeda Inc., USA). The ventilatory reserve (VE/ MVV) was calculated using the indirect (21) maximal voluntary ventilation $\left(\mathrm{MVV}=\mathrm{VEF}_{1} \times 37.5\right)$.

\section{Statistical analysis}

The normal distribution was evaluated by the Kolmogo- 
rov-Smirnov test. Data are reported as mean \pm SD. Comparisons of the variables between rest and each exercise phase were made by repeated measures ANOVA, followed by pre-planned contrasts. Bonferroni correction was used, modifying the level of significance from $P<0.05$ to $P$ $<0.008$ according to the number of contrasts performed (22). The Statistical Package for Social Science (SPSS 13, USA) was used.

\section{Results}

Baseline anthropometric and spirometric values are shown in Table 1. Patients achieved an average maximum workload of $60 \pm 16$ watts and exercise duration of $9.76 \pm$ $3.2 \mathrm{~min}$. Seven patients (32\%) needed to use oxygen during the total time of exercise. Nine $(41 \%)$ patients stopped the exercise due to dyspnea and 13 (59\%) due to leg fatigue.

As expected, VE, Vt, $f$, and the VE/MVV index increased progressively during exercise (Table 2 ).

Both the abdomen and the rib cage contributed to the increase of $\mathrm{Vt}$ as shown in Figure 1. There was a significant correlation between $\mathrm{Vt}$ and the volume related to abdominal and rib cage motion (Figure 2).

The $\% A B$ and $\% R C$ at rest were $50.18 \pm 11.19$ and $49.82 \pm 11.19 \%$, respectively. The $\% A B$ increased in all exercise levels $(64.15 \pm 9.7,63.41 \pm 10$, and $65.56 \pm$ $10.2 \%$ for mild, moderate and maximal exercise, respectively; $\mathrm{P}<0.001$, Figure 3) compared to rest. In conse-

Table 1. Anthropometric and spirometric variables of 22 men with chronic obstructive pulmonary disease.

\begin{tabular}{lccc}
\hline & Mean \pm SD & Minimum & Maximum \\
\hline Age (years) & $68 \pm 8$ & 52 & 79 \\
BMI (kg/m²) & $23 \pm 3$ & 18 & 30 \\
FVC (\%pred) & $74.2 \pm 13.4$ & 51 & 98 \\
FEV $_{1}(\%$ pred) & $42.6 \pm 13.5$ & 25 & 70 \\
FEV $_{1}$ (L) & $1.14 \pm 0.4$ & 0.58 & 2.07 \\
FEV $_{1} /$ FVC (L) & $43.1 \pm 9.6$ & 29 & 62 \\
\hline
\end{tabular}

$\mathrm{BMI}=$ body mass index; FVC = forced vital capacity; $\mathrm{FEV}_{1}=$ forced expiratory volume in $1 \mathrm{~s}$; pred = predicted value.

Table 2. Respiratory variables at rest and during each level of exercise.

\begin{tabular}{lccrr}
\hline Variables & Rest & Mild exercise & Moderate exercise & Maximal exercise \\
\hline VE $(\mathrm{L} / \mathrm{min})$ & $8.4 \pm 2.07$ & $18.49 \pm 6.7^{*}$ & $27.92 \pm 10.10^{*+}$ & $37.69 \pm 13.3^{*+\#}$ \\
Vt $(\mathrm{mL})$ & $463.76 \pm 129.31$ & $911.93 \pm 339.4^{*}$ & $1206.74 \pm 422.7^{*+}$ & $1396.21 \pm 466^{*+\#}$ \\
$f(\mathrm{bpm})$ & $18.73 \pm 3.62$ & $21.08 \pm 4.94^{*}$ & $23.73 \pm 4.74^{*+}$ & $27.56 \pm 4.83^{*+\#}$ \\
VE/MVV & $0.22 \pm 0.11$ & $0.48 \pm 0.22^{*}$ & $0.70 \pm 0.24^{*+}$ & $0.92 \pm 0.26^{*+\#}$ \\
\hline
\end{tabular}

Data are reported as means \pm SD. Mild, moderate and maximal exercise $=30-50,70-80$, and $100 \%$ of maximal workload reached, respectively; $\mathrm{VE}=$ minute ventilation; $\mathrm{Vt}=$ tidal volume; $\mathrm{f}=$ respiratory frequency; $\mathrm{MVV}=$ maximal voluntary ventilation. $\mathrm{N}=22 .{ }^{*} \mathrm{P}<$ 0.008 compared to rest, ${ }^{+} \mathrm{P}<0.008$ compared to previous level and ${ }^{\#} \mathrm{P}<0.008$ compared to mild exercise (repeated measures ANOVA with Bonferroni correction).

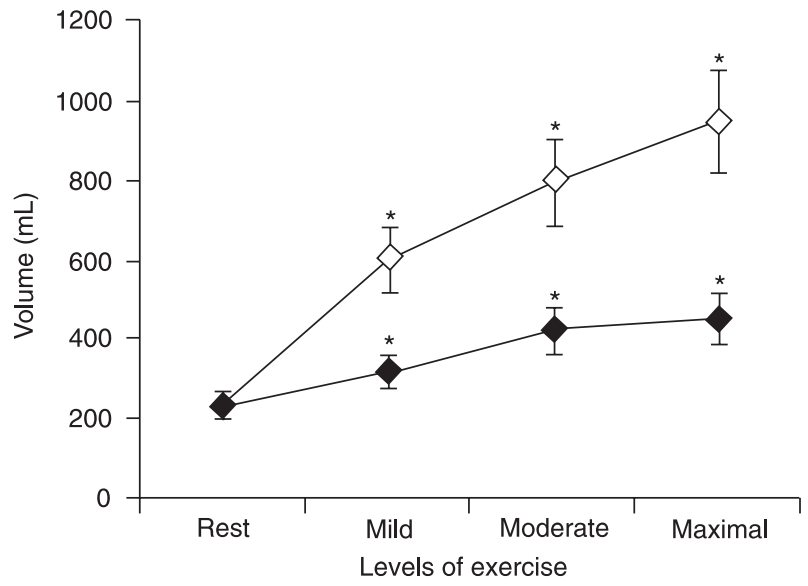

www.bjournal.com.br
Figure 1. The volume related to the motion of the abdomen and the rib cage at rest and during exercise. Mild, moderate and maximal exercise $=30-50,70-80$, and $100 \%$ of maximal workload reached, respectively. Data are reported as means \pm SD for 22 subjects. Open triangles $=$ abdomen motion; closed triangles $=$ rib cage motion. ${ }^{*} \mathrm{P}<0.001$ compared with rest (repeated measures ANOVA with Bonferroni correction). 

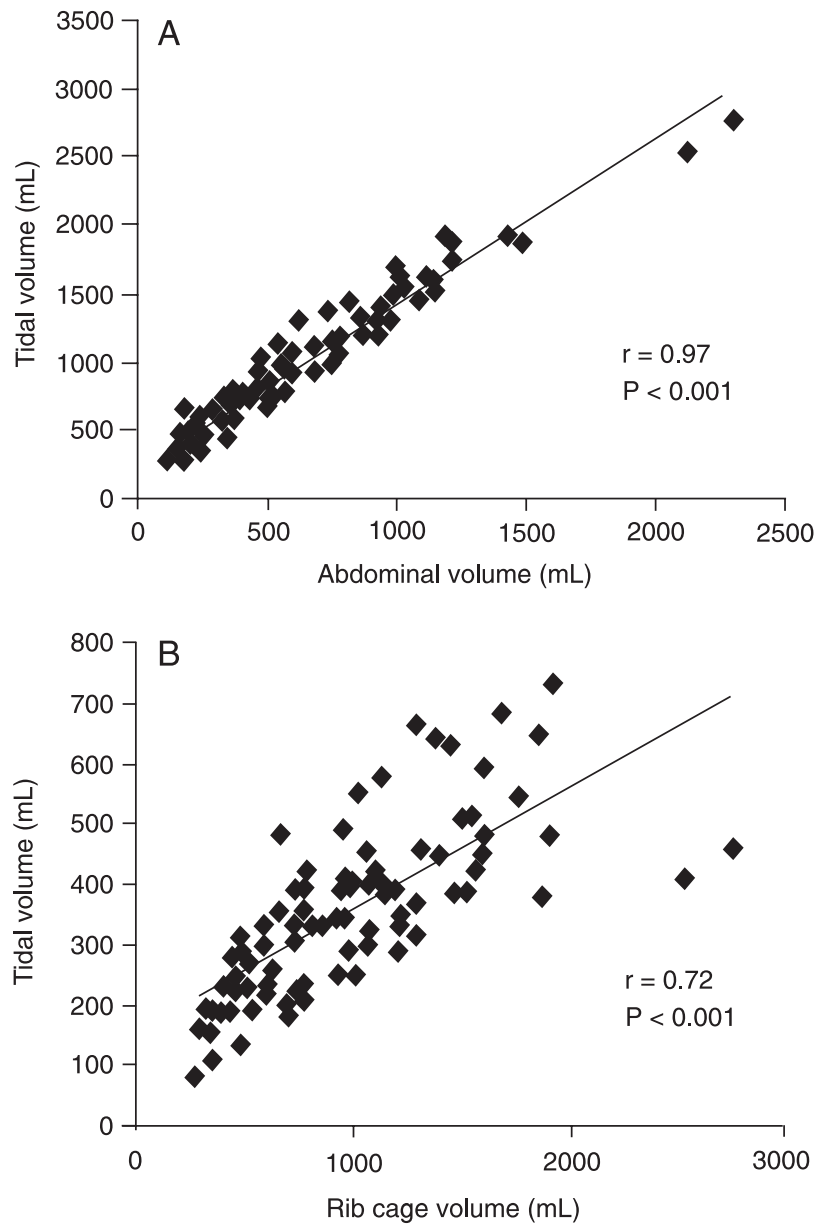

Figure 2. Correlation between tidal volume and volume related to abdominal motion (A) and rib cage motion (B). The Pearson test was used for statistical analysis.

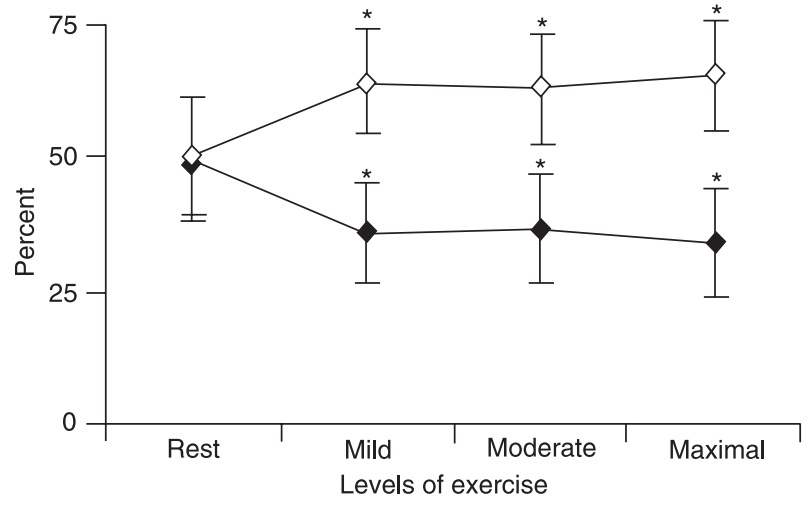

Figure 3. Contribution of abdominal and rib cage motion to tidal volume at rest and during exercise. Mild, moderate and maximal exercise $=30-50,70-80$, and $100 \%$ of maximal workload reached, respectively. Data are reported as means \pm SD for 22 subjects. Open triangles $=$ abdominal motion; closed triangles $=$ rib cage motion. ${ }^{*} \mathrm{P}<0.001$ compared with rest (repeated measures ANOVA with Bonferroni correction). quence, the \%AB/\%RC ratio increased from $1.11 \pm 0.5$ at rest to $2.22 \pm 1(P<0.001)$ at the final level of exercise.

The asynchrony (PhaseAng) increased progressively during exercise, from $11.95 \pm 7^{\circ}$ at rest to $22.2 \pm 15^{\circ}(\mathrm{P}=$ $0.002), 22.6 \pm 9^{\circ}(P<0.001)$ and $22.7 \pm 8^{\circ}(P<0.001)$ during mild, moderate and maximal exercise, respectively.

\section{Discussion}

In this study, we observed greater abdominal motion than rib cage motion in 22 COPD patients during exercise, independent of the exercise intensity. This thoracoabdominal motion behavior was related to increasing $V t$, $f$ and asynchrony.

Our data concerning thoracoabdominal motion confirm results reported in descriptive studies carried out with small samples $(9,10)$. Dodd et al. (9) showed an increase in ventilation during exercise associated with an increase in abdominal volume (from $31 \pm 7$ to $66 \pm 8 \%$ at $50 \%$ and 37 \pm 8 to $52 \pm 5 \%$ at $100 \%$ of maximal work rate, $N=7$ COPD). These authors suggested that the diaphragm plays a major role in generating the greater inspiratory pleural pressure during exercise. Grimby et al. (10) reported increases in the abdominal motion contribution to tidal volume during exercise (from 25 to 30 and $37 \%$ at 300 and 600 kiloponds per minute, respectively, $\mathrm{N}=9 \mathrm{COPD}$ ). In that study, the exercise workload was not individualized. Thus, our data contribute to improve the evidence since the sample was larger and the level of exercise was progressive and individualized.

The passive relaxation of the abdominal muscles after expiration, at the start of inspiration, appeared to be a major contributor to the increases in lung volume and to the predominance of the abdomen during exercise (9). The abdominal motion serves to optimize diaphragm function despite the increase in end expiratory lung volume (EELV) (9).

Dynamic hyperinsuflation increases the ability of the respiratory system to generate expiratory flow but limits the maximum tidal volume and reduces the ability of the inspiratory muscles to produce force by reducing their length. However, Aliverti et al. (3) observed that the exercise limitation in COPD is not necessarily associated with dynamic pulmonary hyperinflation. EELV increased in hyperinflator patients and decreased in non-hyperinflator COPD patients during exercise. Grimby et al. (10) reported that patients who had the most marked increase in EELV showed a decreased relative contribution of the abdomen. Therefore, although we did not measure hyperinflation, we can speculate that, due to increases in abdominal contribution during exercise, the majority of our patients could 
be non-hyperinflator. We also have to consider that the measurement of operational lung volumes such as EELV could contribute to explain the results, but it is impossible to do this by using the respiratory inductive plethysmography.

In the present study, the asynchrony of the thoracoabdominal motion was evaluated by the PhaseAng. PhaseAng values at rest in the supine position were reported for healthy subjects to range from $8^{\circ}(19)$ to $9.8^{\circ}(20)$ and for COPD to be $14.6^{\circ}(20)$. In the present study, we found similar values at rest and an increase during exercise, reflecting the changes in the biomechanics of the respiratory system. No reference values for PhaseAng in COPD patients during exercise were found.

The increased ventilation during exercise may be achieved either by increases in respiratory frequency and/ or in tidal volume. As expected, in the present study, both tidal volume and respiratory frequency contributed to the further increments in ventilation. The higher the intensity of exercise the lower the ventilation reserve. The correlation between tidal volume and abdominal motion during exer- cise supports the role of the expiratory abdominal muscle activity to improve the expiratory flow rates and attenuate hyperinflation.

It should be recognized that the supplementary oxygen could have led to increases in exercise duration and improvement in exercise tolerance. Peters et al. (23) demonstrated that the use of oxygen during exercise reduces dyspnea, increases exercise tolerance, and decreases ventilatory drive. However, Delgado et al. (5) did not observe alterations in thoracoabdominal motion related to the use of oxygen in 11 of 40 patients with COPD during progressive exercise, but that study is not comparable to the present study because it was performed on a treadmill. Thus, it is not possible to be certain that oxygen supplementation had no influence on breathing pattern.

The present study suggests that cycling exercise is an effective way of enhancing the ventilation in COPD patients as observed during diaphragmatic breathing $(7,8)$. However, future studies are necessary to evaluate this response in different groups of COPD according to the severity of the disease.

\section{References}

1. Nici L, Donner C, Wouters E, ZuWallack R, Ambrosino N, Bourbeau J, et al. American Thoracic Society/European Respiratory Society statement on pulmonary rehabilitation. Am J Respir Crit Care Med 2006; 173: 1390-1413.

2. O'Donnell DE, Lam M, Webb KA. Measurement of symptoms, lung hyperinflation, and endurance during exercise in chronic obstructive pulmonary disease. Am J Respir Crit Care Med 1998; 158: 1557-1565.

3. Aliverti A, Stevenson N, Dellaca RL, Lo Mauro A, Pedotti A, Calverley PM. Regional chest wall volumes during exercise in chronic obstructive pulmonary disease. Thorax 2004; 59: 210-216

4. Sharp JT, Goldberg NB, Druz WS, Fishman HC, Danon J. Thoracoabdominal motion in chronic obstructive pulmonary disease. Am Rev Respir Dis 1977; 115: 47-56.

5. Delgado HR, Braun SR, Skatrud JB, Reddan WG, Pegelow DF. Chest wall and abdominal motion during exercise in patients with chronic obstructive pulmonary disease. Am Rev Respir Dis 1982; 126: 200-205.

6. Gosselink R. Controlled breathing and dyspnea in patients with chronic obstructive pulmonary disease (COPD). $J$ Rehabil Res Dev 2003; 40: 25-33.

7. Grimby G, Oxhoj H, Bake B. Effects of abdominal breathing on distribution of ventilation in obstructive lung disease. $J$ Rehab Sci 1993; 6: 66-87.

8. Sackner MA, Gonzalez HF, Jenouri G, Rodriguez M. Effects of abdominal and thoracic breathing on breathing pattern components in normal subjects and in patients with chronic obstructive pulmonary disease. Am Rev Respir Dis 1984; 130: 584-587.

9. Dodd DS, Brancatisano T, Engel LA. Chest wall mechanics during exercise in patients with severe chronic air-flow obstruction. Am Rev Respir Dis 1984; 129: 33-38.

10. Grimby G, Elgefors $B$, Oxhoj $H$. Ventilatory levels and chest wall mechanics during exercise in obstructive lung disease. Scand J Respir Dis 1973; 54: 45-52.

11. Rabe KF, Hurd S, Anzueto A, Barnes PJ, Buist SA, Calverley $P$, et al. Global strategy for the diagnosis, management, and prevention of chronic obstructive pulmonary disease: GOLD executive summary. Am J Respir Crit Care Med 2007; 176: 532-555.

12. Yan $S$, Kaminski D, Sliwinski P. Inspiratory muscle mechanics of patients with chronic obstructive pulmonary disease during incremental exercise. Am J Respir Crit Care Med 1997; 156: 807-813.

13. Cooper CB. Pulmonary disease. In: American College of Sports Medicine (Editor), ACSM'S exercise management for persons with chronic diseases and disabilities. USA: Human Kinetics; 1997. p 74-77.

14. McConnell TR. Cardiorespiratory assessment of apparently healthy populations. In: Anonimous (Editor), ACSM's resource manual for guidelines for exercise testing and prescription. 3rd edn. Baltimore: Lippincott Williams \& Wilkins; 1998. p 347-353.

15. Chadha TS, Watson H, Birch S, Jenouri GA, Schneider AW, Cohn MA, et al. Validation of respiratory inductive plethys- 
mography using different calibration procedures. Am Rev Respir Dis 1982; 125: 644-649.

16. Teramoto $S$, Fukuchi $Y$, Nagase $T$, Matsuse $T$, Orimo $H$. A comparison of ventilation components in young and elderly men during exercise. J Gerontol A Biol Sci Med Sci 1995; 50A: B34-B39.

17. Sackner MA, Watson $H$, Belsito AS, Feinerman $D$, Suarez $M$, Gonzalez G, et al. Calibration of respiratory inductive plethysmograph during natural breathing. J Appl Physiol 1989; 66: 410-420.

18. Parreira VF, Tomich GM, Britto RR, Sampaio RF. Assessment of tidal volume and thoracoabdominal motion using volume and flow-oriented incentive spirometers in healthy subjects. Braz J Med Biol Res 2005; 38: 1105-1112.

19. Bloch KE, Barandun J, Sackner MA. Effect of mouthpiece breathing on cardiorespiratory response to intense exer- cise. Am J Respir Crit Care Med 1995; 151: 1087-1092.

20. Sackner MA, Gonzalez H, Rodriguez M, Belsito A, Sackner DR, Grenvik S. Assessment of asynchronous and paradoxic motion between rib cage and abdomen in normal subjects and in patients with chronic obstructive pulmonary disease. Am Rev Respir Dis 1984; 130: 588-593.

21. Neder JA, Andreoni S, Lerario MC, Nery LE. Reference values for lung function tests. II. Maximal respiratory pressures and voluntary ventilation. Braz J Med Biol Res 1999; 32: 719-727.

22. Munro BH. Statistical methods for health care research. 4th edn. Baltimore: Lippincott; 2001.

23. Peters MM, Webb KA, O'Donnell DE. Combined physiological effects of bronchodilators and hyperoxia on exertional dyspnoea in normoxic COPD. Thorax 2006; 61: 559-567. 